\title{
Erratum to: Complex Formation of Crown Ethers and Cations in Water-Organic Solvent Mixtures: Part XI. Effects of the Preferential Solvation of Benzo-15-Crown-5 and Acid-Base Properties of the Mixtures on the Thermodynamic Functions for Complex Formation of Benzo-15-Crown-5 with $\mathrm{Na}^{+}$ in Propan-1-ol-Water Mixtures at 298.15 K
}

\author{
Małgorzata Jóźwiak • Adam Bald • Andrzej Jóźwiak
}

Published online: 1 December 2009

(C) Springer Science+Business Media, LLC 2009

Erratum to: J Solution Chem (2009) 38: 1283-1294

DOI 10.1007/s10953-009-9446-8

On page 1284, the second sentence of Sect. 2 should read: "The purity of B15C5 is $>0.99$ mole fraction and it was determined with a TG DSC 111 (SETARAM) with indium as a standard."

On page 1291, the next to last sentence should read: "Thus, one can assume that this is not due to experimental errors but it is connected with the process of hydrophobic hydration of the crown ether and $\mathrm{PrOH}$ by the water molecules in the range $x_{\mathrm{w}} \geq 0.6$."

The online version of the original article can be found under doi:10.1007/s10953-009-9446-8.

M. Jóźwiak (凶)

Department of Physical Chemistry, University of Lodz, ul. Pomorska 165, 90-236 Lodz, Poland e-mail:mjozwiak@uni.lodz.pl

A. Bald

Department of Physical Chemistry of Solutions, University of Lodz, ul. Pomorska 163, 90-236 Lodz, Poland

A. Jóźwiak

Department of Organic Chemistry, University of Lodz, ul. Narutowicza 68, 90-136 Lodz, Poland 